\title{
Influence of Fatty Acid Methyl Ester Composition, Acid Value, and Water Content on Metallic Copper Corrosion Caused by Biodiesel
}

\author{
José G. Rocha Jr., ${ }^{\oplus a}$ Marcelle D. R. dos Santos, ${ }^{b}$ Fernanda B. Madeira, ${ }^{a}$ \\ Sheisi F. L. S. Rocha, ${ }^{a}$ Glauco F. Bauerfeldt, ${ }^{a}$ Willian L. G. da Silva, ${ }^{c}$ \\ Acácia A. Salomão ${ }^{c}$ and Matthieu Tubino ${ }^{\circledR *, c}$ \\ ${ }^{a}$ Instituto de Química, Universidade Federal Rural do Rio de Janeiro, \\ BR-465, km 7, 23897-000 Seropédica-RJ, Brazil \\ ${ }^{b}$ Departamento de Engenharia Química, Universidade Federal Rural do Rio de Janeiro, \\ BR-465, km 7, 23897-000 Seropédica-RJ, Brazil \\ 'Instituto de Química, Universidade Estadual de Campinas, CP 6154, \\ 13083-970 Campinas-SP, Brazil
}

\begin{abstract}
Oxidative stability parameters (OSP), acid value (AV), water content (W), and the metallic copper corrosion rate in biodiesels obtained from eight different vegetable oils were determined. Simple and multiple linear regression models were constructed to explain the influence of the OSP, AV and $\mathrm{W}$ variables on the corrosion rate. The corrosion rate was lower in biodiesel with less oxidative stability because, instead of reacting with copper, $\mathrm{O}_{2}$ reacted preferentially with the unsaturated fatty acid methyl esters (FAME) that could act as "sacrificial molecules" to protect the copper against corrosion. Therefore, the corrosion rate was strongly related to the FAME composition. The AV was an important parameter in the corrosion process because free acids react with passivating agents, increasing the corrosion rate. The predictive capacity of $\mathrm{W}$ for corrosion rate was statistically insignificant, although water condensed on a copper surface causes corrosion.
\end{abstract}

Keywords: oxidative stability, corrosion, multiple linear regression, unsaturated FAME

\section{Introduction}

Biodiesel is currently an excellent alternative vehicle fuel for sustainability. It can be used in pure form or mixed in any proportion with diesel, forming a diesel-biodiesel binary mixture. ${ }^{1,2}$ Usually, diesel-biodiesel blends with low volume percent biodiesel are used in diesel engines. In some countries, such as the United States, Australia and Indonesia, this percentage reaches $20 \%$ (B20). ${ }^{3-5}$ The European Standard EN $16709^{6}$ specifies requirements and test methods for B30 marketed and delivered for use in diesel engines that are specially designed or adapted. However, in other countries, as in Brazil, this percentage is only $10 \%$ (B10). ${ }^{7}$ This is due, among other reasons, to the incompatibility of materials that make up the fuel circuit of diesel engines. ${ }^{8}$

Despite the advantages of biodiesel over diesel, biodiesel is significantly more susceptible to degradation, which often makes it more corrosive than diesel. ${ }^{8,9}$ The degradation

*e-mail: tubino@iqm.unicamp.br of biodiesel is mainly due to auto-oxidation reactions, moisture absorption, and the attack of microorganisms during the storage and use of biodiesel, ${ }^{10,11}$ and it may be more pronounced depending on the raw material as a consequence of differences in chemical composition, mainly in relation to the degree of instauration. The oxidation rate of biodiesel is more influenced by the composition of its alkyl esters than by environmental conditions (temperature, air, light, and the presence of metals). ${ }^{12} \mathrm{~A}$ lower oxidative stability is obtained when a greater quantity of double bonds is present in the methyl ester. Allylic sites are especially susceptible to oxidation and bis-allylic sites are even more so. An allylic site shows a methylene $\mathrm{CH}_{2}$ group adjacent to only one double bond. A methylene $\mathrm{CH}_{2}$ group located between two double bonds is a bis-allylic site. ${ }^{13}$

In some studies on alkyl ester mixtures, oxidative stability was observed to depend strongly on the concentrations of linoleic and linolenic alkyl esters (polyunsaturated alkyl esters), rather than on the concentrations of saturated and monounsaturated alkyl esters, even if the latter are in greater proportion than the former in the biodiesel mixture. Most 
biodiesel fuels contain significant amounts of oleic (C18:1), linoleic (C18:2) or linolenic (C18:3) acid esters, that have 2 allylic sites and 0,1 , and 2 bis-allylic sites, respectively, decreasing the oxidative stability of the fuel. According to Knothe and Dunn, the relative rates of oxidation for these esters are 1 for oleates, 41 for linoleates, and 98 for linolenates. ${ }^{14}$

Short carbon chain acids formed at the end of biodiesel's degradation process, such as formic, acetic, propionic, and caproic acids, have been reported as responsible for the corrosion of the fuel supply system of the engine, ${ }^{10,13,15,16}$ suggesting that the biodiesel corrosiveness is inversely correlated with its oxidative stability. The corrosion of metals can trigger and catalyze other undesirable reactions leading to the instability and degradation of biodiesel, ${ }^{17,18}$ making it more corrosive. Reports can be found in the literature demonstrating the influence of the fatty acid methyl ester (FAME) composition on the oxidative stability of biodiesel, but not directly related to its corrosiveness. ${ }^{12-14}$ There is only a consensus that the corrosiveness of biodiesel is inversely proportional to its oxidative stability; however, this proposal is not supported by experimental data.

The presence of impurities, such as alcohol, free fatty acids (FFA), water, catalyst, and glycerol that remain at the end of the transesterification reaction was also reported as responsible for biodiesel corrosiveness. ${ }^{18}$ Additionally, as biodiesel is more hygroscopic than diesel, water can condense on the internal metal surfaces of the engine, favoring corrosion reactions and promoting microbial growth that causes additional corrosion. ${ }^{10}$

Copper is a component of the materials used for the production, storage, and transportation of biodiesel due to its excellent electrical and thermal properties, good mechanical workability, and good alloying ability. However, in biodiesel media, it easily undergoes corrosion, which undermined the long-term durability of piping and storage tanks. ${ }^{19}$ Besides, diesel engine parts like fuel pump, bearing, bushing, etc. are composed by copper alloy. Therefore, they are extensively influenced by corrosion ocasionated by biodiesel..$^{20,21}$ Sgroi et al..$^{22}$ evaluated the corrosive effect of biodiesel on sintered bronze filter of an oil nozzle. The authors found that pitting corrosion occurred on bronze when the nozzle operated at $70{ }^{\circ} \mathrm{C}$ for several hours. Researchers observed that copper alloys are prone to be corroded by biodiesel compared to ferrous alloys and aluminum alloys. ${ }^{21,23}$

Fazal et al. ${ }^{24}$ reported that $\mathrm{O}_{2}, \mathrm{H}_{2} \mathrm{O}, \mathrm{CO}_{2}$, and $\mathrm{RCOO} \bullet$ radicals dissolved in biodiesel are key factors that can affect its corrosiveness. They proposed a mechanism for the corrosion of metallic copper after performing a series of immersion tests on palm biodiesel at room temperature $\left(25-27^{\circ} \mathrm{C}\right)$. These authors found that the oxidation of the metallic surface is done primarily by $\mathrm{O}_{2}$, which produces $\mathrm{Cu}_{2} \mathrm{O}$ and $\mathrm{CuO}$. In presence of $\mathrm{H}_{2} \mathrm{O}, \mathrm{Cu}(\mathrm{OH})_{2}$ is formed and, if $\mathrm{CO}_{2}$ or $\mathrm{RCOO} \bullet$ radicals are present, $\mathrm{CuCO}_{3}$ is also produced. These solid compounds are formed on the metal surface constituting layers that protect the metal against posterior oxidation, reducing the corrosion rate. Therefore, the water and dissolved oxygen contents in the fuel are important factors that increase the corrosiveness of biodiesel, while $\mathrm{RCOO} \bullet$ radicals and $\mathrm{CO}_{2}$ act as inhibitors.

Aquino et $\mathrm{al}^{25}{ }^{25}$ noted that the induction period (IP) of commercial biodiesel after the immersion at $55^{\circ} \mathrm{C}$ of the copper and brass decreases from 8 to $0.05 \mathrm{~h}$, revealing that the metallic ions present in the biodiesel, $\mathrm{Cu}^{2+}$ and $\mathrm{Zn}^{2+}$ ions, have a strong catalytic effect on the degradation reactions, regardless of the conditions of light and temperature and metallic ions concentration. Sarin et al. ${ }^{26}$ have undertaken studies on stability of the neat Jatropha biodiesel in the presence of transition metals (iron, nickel, manganese, cobalt, and copper), likely to be present in the metallurgy of storage tanks and barrels. They found that influence of the metal was detrimental to oxidation stability and catalytic. Even small concentrations of metal contaminants showed nearly same influence on oxidation stability as large amounts. Copper showed the strongest detrimental and catalytic effect.

The objective of this work is to investigate the direct influence that the FAME composition exerts on biodiesel corrosiveness by measuring the mass loss of metallic copper plates after immersing them in biodiesels produced from different raw materials. Moreover, acid value (AV), water content $(\mathrm{W})$, and some parameters associated to the oxidative stability of each biodiesel will be used for the construction of multiple linear regression (MLR) models in order to evaluate the relevance of these parameters in biodiesel corrosivity.

\section{Experimental}

\section{Materials}

For the synthesis of biodiesels, soybean, canola, linseed, sunflower, and corn oils were purchased in the local market. Macauba kernel oil was acquired from the Association of Small Scale Producers in the city of Riacho Dantas, Montes Claros, Minas Gerais, Brazil. Used frying oil was generously donated by the Environment Division of the University of Campinas. Palm kernel oil was acquired from the Agropalma company (Belém-PA, Brazil). Methanol, $99.8 \%$ purity, was supplied by Synth (Diadema-SP, Brazil) and $30 \%(\mathrm{~m} / \mathrm{m})$ sodium methoxide in methanol from 
Vetec (Rio de Janeiro-RJ, Brazil) was used. For the final purification of the produced biodiesel Amberlite BD10 Dry, a sulfonic acid resin from Dow Chemical company (USA), was used. Thick electrolytic copper foils of $0.30 \mathrm{~mm}$ thickness were employed to perform corrosion tests. A mix of 14 fatty acid methyl ester standards, C8 to C24, was purchased from Supelco (Bellefonte, PA, USA). It was used for the confirmation of the retention time of each fatty acid methyl ester in the chromatograms.

\section{Biodiesel synthesis}

The synthesis of the biodiesels was performed in three steps. First, $16 \%(\mathrm{~m} / \mathrm{m})$ of methanol and $0.58 \% \mathrm{~m} / \mathrm{m}$ of a methanolic solution of sodium methoxide $(30 \% \mathrm{~m} / \mathrm{m})$ were mixed to the oil. The solution was maintained at $60{ }^{\circ} \mathrm{C}$ with mechanical stirring (900 rpm) for $1 \mathrm{~h}$. Then, the reaction mixture was transferred to a separatory funnel for separation of the glycerin phase. In the second step, the upper phase was returned to the reaction flask, to which $4 \%(\mathrm{~m} / \mathrm{m})$ of methanol and $0.14 \%(\mathrm{~m} / \mathrm{m})$ of the catalyst solution were added (with respect to the initial mass of oil). The reaction was then carried out as in the first step.

In the third step, the biodiesel obtained in the second step was washed with five portions of water $(50 \mathrm{~mL})$ at $60{ }^{\circ} \mathrm{C}$ and then dried at $100{ }^{\circ} \mathrm{C}$ in an oven for $1 \mathrm{~h}$. The biodiesel was then passed through a column containing Amberlite BD10 Dry resin to remove any impurities. In this scheme, $180 \mathrm{~g}$ of resin was employed per liter of biodiesel, and the percolation was performed at a flow rate of $4 \mathrm{~mL} \mathrm{~min}^{-1}$.

For macauba, palm, and used frying oils, before performing the transesterification reaction, a prior step of FFA esterification was necessary. FFA are present in relatively high concentrations in these kinds of oils, which is evidenced by their high AVs. The esterification step was performed by adding, with respect to the initial mass of oil, $24 \%(\mathrm{~m} / \mathrm{m})$ of methanol and $1 \%(\mathrm{~m} / \mathrm{m})$ of concentrated sulfuric acid. The reaction mixture was heated at $50^{\circ} \mathrm{C}$ and stirred at $900 \mathrm{rpm}$ for one hour.

\section{Analytical methods}

The FAME composition of the biodiesel used for the experiments was determined using gas chromatographymass spectrometry (GC-MS). An Agilent Technologies 5890A GC System (China) and Agilent Technologies 5975C inert XL MSD (China) with Agilent Technologies 7693 autosampler (China) were used under the following conditions: Agilent DB23 column (50\% cyanopropylmethylpolysiloxane) $30 \mathrm{~m}$ long, $0.25 \mathrm{~mm}$ internal diameter, $0.25 \mu \mathrm{m}$ film thickness; split injection 1:200; injection volume $1 \mu \mathrm{L}$; injector temperature $250^{\circ} \mathrm{C}$; initial temperature of the oven $60^{\circ} \mathrm{C}$, held for $1 \mathrm{~min} ; 16^{\circ} \mathrm{C} \mathrm{min}^{-1}$ heating rate up to $140{ }^{\circ} \mathrm{C}$, held for $2 \mathrm{~min} ; 0.5^{\circ} \mathrm{C} \mathrm{min}{ }^{-1}$ heating rate up to $150{ }^{\circ} \mathrm{C}$; and $16{ }^{\circ} \mathrm{C} \mathrm{min}^{-1}$ heating rate up to $250{ }^{\circ} \mathrm{C}$, held for $1 \mathrm{~min}$; auxiliary oven at $250{ }^{\circ} \mathrm{C}$. The mass spectrometer was operated with $\mathrm{EI} 70 \mathrm{eV}$ (electron ionization), the solvent delay was $4 \mathrm{~min}$, and the scanning range was $50-400 \mathrm{~m} / \mathrm{z}$. Peak identification was done by comparing the obtained mass spectra with those of the NIST11.L database and confirmed by comparing with the retention time of methyl ester standards. The quantitation was obtained through the normalization of the area under each chromatographic peak.

The induction period, IP, which expresses the oxidative stability, was determined in duplicate following the EN 14112 method, ${ }^{27}$ using a model 873 Biodiesel Metrohm Rancimat (Switzerland).

The W was determined according to the EN ISO 12937 method, ${ }^{28}$ using a model $831 \mathrm{KF}$ Metrohm Karl Fischer coulometric titrator (Switzerland). The measurements were performed in triplicate.

The AV was determined following the method proposed by Aricetti and Tubino. ${ }^{29}$ To perform the titration, a Metrohm Titrando 809 device (Switzerland) equipped with a Metrohm Solvotrode electrode (Switzerland) (electrolyte, saturated solution of $\mathrm{LiCl}$ in ethanol) and a Metrohm 814 USB Sample Processor (Switzerland) automatic sampler was used. All measurements were performed in duplicate.

\section{Corrosion tests}

Copper foil pieces $(20 \times 20 \times 0.30 \mathrm{~mm})$ were polished with $\mathrm{SiC} 420$ and 220 grids sandpapers and subsequently sized with the aid of a caliper rule. According to ASTM G1-03 recommendations, ${ }^{30}$ the copper foils were brushed with a nylon bristle brush, washed with distilled water, ethanol, and acetone, dried with hot air, and kept in a desiccator. The individual masses of the copper plates were determined on an analytical balance $( \pm 0.00001 \mathrm{~g})$. The washing and drying procedure was repeated for each piece until constant mass. Each copper plate was immersed, held suspended by a Nylon ${ }^{\circledR}$ thread, in $50 \mathrm{~mL}$ of biodiesel and maintained in an oven at $60{ }^{\circ} \mathrm{C}$. On the sixth day, the biodiesels were submitted to vigorous stirring with a magnetic stir bar for $15 \mathrm{~min}$. After that, the plates were maintained in an oven at $60^{\circ} \mathrm{C}$ for more six days for a total of $288 \mathrm{~h}$ of immersion. The aim of the agitation was to promote the aeration of biodiesel replacing the oxygen consumed in the oxidation reactions. Otherwise, the corrosion rate may be low enough to hamper the mass loss measures. 
The copper plates were then removed from the biodiesels, brushed, and washed with distilled water and ethanol. A solution of $10 \%(\mathrm{v} / \mathrm{v})$ sulfuric acid was used to remove the corrosion products from the copper surface. The immersion time for pickling was $3 \mathrm{~min}$. After the chemical treatment, the plates were washed with distilled water and acetone, dried with hot air, using a hair dryer, and finally weighed on an analytical balance. Cleaning procedures were also performed on copper plates to obtain the blank of corrosion rate. The water washing and drying procedures were repeated until constant mass. All assays were performed in triplicate. The average corrosion rate (in $\mathrm{mg} \mathrm{m}^{-2} \mathrm{~h}^{-1}$ ) was obtained using equation 1 , as follows:

corrosion rate $=\left(\Delta \mathrm{m} \times 10^{4}\right) /(\mathrm{A} \times \mathrm{t})$

where: $\Delta \mathrm{m}$ is the loss of mass, in $\mathrm{mg}$; $\mathrm{A}$ is the total area of the copper plate, in $\mathrm{cm}^{2}$; $\mathrm{t}$ is the time of immersion, in $\mathrm{h}$; and $10^{4}$ is the conversion factor to convert $\mathrm{cm}^{-2}$ to $\mathrm{m}^{-2}$.

\section{Results and Discussion}

\section{Influence of FAME composition on corrosion rate}

The corrosion rates of metallic copper are shown in Figure 1. According to these results, the biodiesel from used frying oil, macauba and palm kernel were the most corrosive among the studied biodiesels whereas those from canola, sunflower, and soybean oils presented relatively less corrosivity.

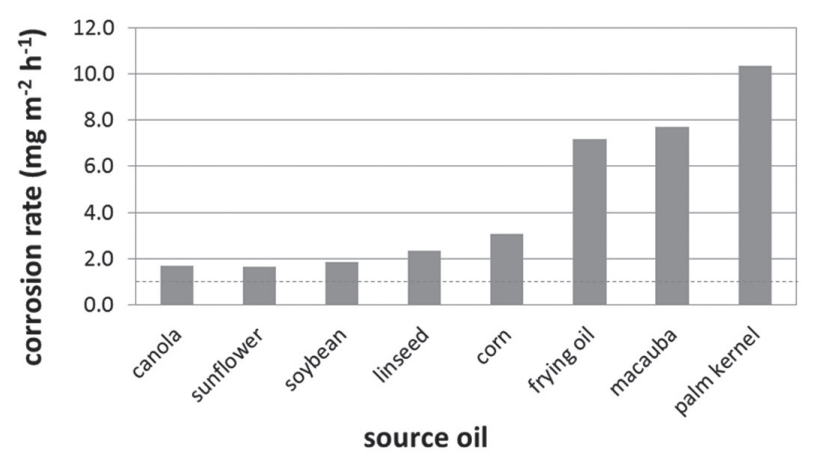

Figure 1. Corrosion rates on metallic copper immersed in biodiesel from different vegetable oils. The dotted line is the corrosion of the blank samples.

The compositional analysis in Table 1 revealed that the biodiesel corrosivity is related to the methyl esters of oleic (C18:1), linoleic (C18:2) and linolenic (18:3) acids, more specifically the level of unsaturated methyl esters. Soybean, sunflower, canola, linseed, and corn biodiesel were composed mainly of $\mathrm{C} 18: 1, \mathrm{C} 18: 2$, and $\mathrm{C} 18: 3$, that correspond to $84.7 \%$ (for soybean) to $95.1 \%$ (for canola) of FAME content. These biodiesels were the least corrosive (Figure 1). Used frying oil, macauba, and palm kernel biodiesels were poorer in C18:1, C18:2, and C18:3, having from $22.0 \%$ (for macauba) to $35.1 \%$ (for palm kernel) of these esters in their composition. Additionally, they exhibited a high composition of saturated chain esters ( 45.3 to $66.7 \%$ ). These biodiesels were the most corrosive (Figure 1).

These results suggest that if, on the one hand, methyl esters of oleic, linoleic and linolenic acids have a negative effect on biodiesel quality by causing a decrease in their oxidative stability, ${ }^{12}$ on the other hand, these esters make the biodiesel less corrosive.

Influence of W, AV, and oxidative stability parameters (OSP) on corrosion rate

Although the corrosion rate is apparently well related to the presence of the $\mathrm{C} 18: 1, \mathrm{C} 18: 2$, and $\mathrm{C} 18: 3$ esters, the $\mathrm{W}, \mathrm{AV}$, and IP of prepared biodiesel (Table 2) should also be considered, since these parameters are related to the corrosivity of the biodiesel. ${ }^{9,11-14,16}$ In order to find out which parameters affect biodiesel corrosiveness, it is important to verify the relationship of the corrosion rate with each of them.

The comparison of the metallic copper corrosion rate versus $\mathrm{W}$ of biodiesel (Figure 2a) suggests that there is some correlation $(\mathrm{r}=-0.50)$. Despite being low, two suggestions can be obtained from this correlation coefficient. First, due to the low level of correlation, this parameter could not be considered an important cause of the corrosivity of the investigated biodiesel. Second, paradoxically, by the negative sign of the correlation coefficient, the corrosivity of the biodiesel decreases with the increase of its W as a general trend. This observation disagrees with previous observations where it was found that an increase of W results in more corrosive biodiesel. ${ }^{9}$ However, the corrosion rates are also affected by the other parameters besides $\mathrm{W}$, which could be causing this behavior. A multiple linear regression model may be more appropriate to describe the relationship between $\mathrm{W}$ and the corrosion rate.

The correlation between the corrosion rate and $\mathrm{AV}$ is shown in Figure 2b. A higher correlation $(r=0.76)$, than was found with the $\mathrm{W}$, was observed. This clearly indicates that $\mathrm{AV}$ is an important parameter in the corrosion process under study, as was also found by other researchers. ${ }^{10,13,15,16}$

IP was employed for evaluating the relationship between the corrosion rate and the oxidative stability of biodiesel. The IP value indicates the effect of the global composition of the biodiesel, including the FAME composition, the FFA contents, water, peroxides, catalysts, 
Table 1. Compositional analysis of biodiesels, related oxidative stability parameters (OSP = APE, BAPE, and OX indices), and $\mathrm{N}_{\mathrm{UNSAT}}$

\begin{tabular}{|c|c|c|c|c|c|c|c|c|}
\hline \multirow[b]{2}{*}{ FAME } & \multicolumn{8}{|c|}{ Source oil } \\
\hline & Used frying oil & Macauba & Palm kernel & Soybean & Corn & Sunflower & Canola & Linseed \\
\hline $\mathrm{C} 8: 0$ & - & 2.15 & 3.34 & - & - & - & - & - \\
\hline C10:0 & - & 2.43 & 3.14 & - & - & - & - & - \\
\hline C12:0 & - & 43.92 & 36.52 & - & - & - & - & - \\
\hline $\mathrm{C} 14: 0$ & - & 16.88 & 11.03 & - & - & - & - & - \\
\hline $\mathrm{C} 16: 0$ & 8.28 & 10.14 & 8.80 & 10.98 & 12.20 & 4.22 & 4.86 & 4.90 \\
\hline C16:1 & 8.35 & 0.02 & 0.08 & 0.09 & - & - & - & - \\
\hline $\mathrm{C} 17: 0$ & 8.67 & - & 0.03 & 0.09 & - & - & - & - \\
\hline $\mathrm{C} 17: 1$ & 8.74 & - & 0.02 & 0.05 & - & - & - & - \\
\hline C18:0 & 9.07 & 2.26 & 3.75 & 3.27 & 1.60 & 2.69 & - & 2.90 \\
\hline C18:1 & 9.14 & 19.35 & 29.68 & 23.33 & 36.40 & 42.80 & 65.80 & 31.30 \\
\hline $\mathrm{C} 18: 2$ & 9.28 & 2.65 & 3.37 & 54.78 & 49.80 & 50.30 & 22.55 & 18.90 \\
\hline $\mathrm{C} 18: 3$ & 9.44 & - & - & 6.57 & - & - & 6.75 & 42.00 \\
\hline $\mathrm{C} 20: 0$ & 9.39 & 0.12 & 0.13 & 0.30 & - & - & - & - \\
\hline C20:1 & 9.79 & 0.08 & 0.11 & 0.19 & - & - & - & - \\
\hline C22:0 & 9.85 & - & - & 0.34 & - & - & - & - \\
\hline $\mathrm{APE} /(\%)$ & 110 & 44.2 & 66.5 & 170 & 172 & 186 & 190 & 184 \\
\hline BAPE / (\%) & 28.2 & 2.65 & 3.37 & 67.9 & 49.8 & 50.3 & 36.1 & 103 \\
\hline OX & 0.283 & 0.0304 & 0.0396 & 0.684 & 0.505 & 0.512 & 0.373 & 1.04 \\
\hline $\mathrm{N}_{\text {UNSAT }}$ & 0.829 & 0.248 & 0.366 & 1.53 & 1.36 & 1.43 & 1.31 & 1.95 \\
\hline
\end{tabular}

FAME: fatty acid methyl ester; APE: allylic position equivalent; BAPE: bis-allylic position equivalent; OX: oxidability; $\mathrm{N}_{\mathrm{UNSAT}}$ : number of unsaturated bonds.

Table 2. Water content, acid value, and induction period of the prepared biodiesels

\begin{tabular}{lccc}
\hline Source oil & Water content $/\left(\mathrm{mg} \mathrm{kg}^{-1}\right)$ & Acid value $/\left(\mathrm{mg} \mathrm{g}^{-1}\right)^{\mathrm{a}}$ & Induction period / h \\
\hline Sunflower & $509 \pm 7$ & $0.096 \pm 0.004$ & $3.1 \pm 0.2$ \\
Canola & $660 \pm 18$ & $0.103 \pm 0.002$ & $6.9 \pm 0.3$ \\
Corn & $518 \pm 13$ & $0.129 \pm 0.003$ & $7.6 \pm 0.1$ \\
Linseed & $809 \pm 11$ & $0.15 \pm 0.01$ & $2.00 \pm 0.01$ \\
Used frying oil & $385 \pm 11$ & $0.17 \pm 0.01$ & $1.61 \pm 0.02$ \\
Soybean & $249 \pm 4$ & $0.201 \pm 0.008$ & $6.0 \pm 0.2$ \\
Macauba & $187 \pm 16$ & $0.204 \pm 0.008$ & $64.3 \pm 0.3$ \\
Palm kernel & $394 \pm 5$ & $0.240 \pm 0.003$ & $54 \pm 3$ \\
\hline
\end{tabular}

${ }^{\mathrm{a}}$ Milligrams of $\mathrm{KOH}$ per gram of biodiesel.

glycerol, methanol, natural antioxidants, etc., on its oxidative stability. To investigate the relationship between biodiesel corrosivity and the oxidative stability related only to the FAME composition, the parameters proposed by Knothe $^{31}$ and Neff et al ${ }^{32}$ were employed. These authors have demonstrated that the oxidability of biodiesel, in terms of FAME composition, could be estimated by APE (allylic position equivalent), BAPE (bis-allylic position equivalent), and OX (oxidizability) indices, according to equations 2-4 (the first two are written in their generalized form):
$\mathrm{APE}=\mathrm{ap}_{\mathrm{a}} \mathrm{A}_{\mathrm{Ca}}+\mathrm{ap}_{\mathrm{b}} \mathrm{A}_{\mathrm{Cb}}+\mathrm{ap}_{\mathrm{c}} \mathrm{A}_{\mathrm{Cc}}+\ldots$

$\mathrm{BAPE}=\mathrm{bp}_{\mathrm{a}} \mathrm{A}_{\mathrm{Ca}}+\mathrm{bp}_{\mathrm{b}} \mathrm{A}_{\mathrm{Cb}}+\mathrm{bp}_{\mathrm{c}} \mathrm{A}_{\mathrm{Cc}}+\ldots$

$\mathrm{OX}=[0.02(\mathrm{C} 18: 1)+(\mathrm{C} 18: 2)+2(\mathrm{C} 18: 3)] / 100$

where: $\mathrm{ap}_{\mathrm{x}}$ and $\mathrm{bp}_{\mathrm{x}}$ are the number of allylic and bis-allylic positions, respectively, in a specific FAME; $A_{C x}$ is the percentage content of each FAME in biodiesel; C18:1, C18:2, and $\mathrm{C} 18: 3$ are the percentage content of methyl esters of oleic, linoleic and linolenic acids. The APE, BAPE and OX indices calculated by equations 2-4 are listed in Table 1 . 
(a)

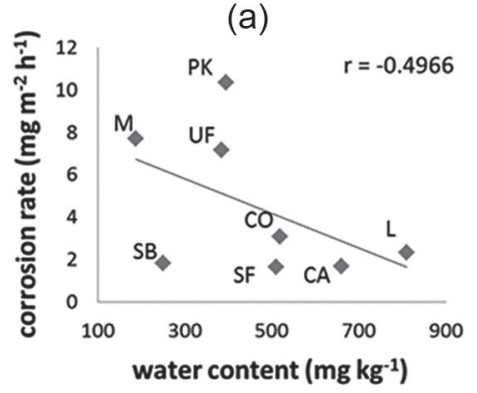

(d)

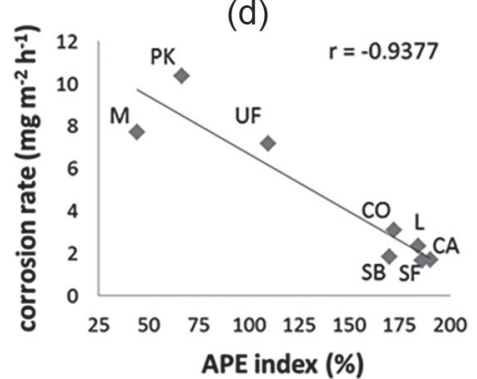

(b)

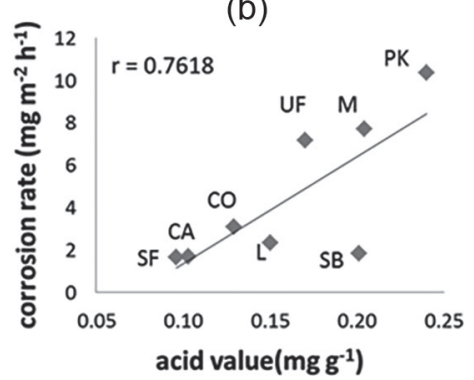

(e)

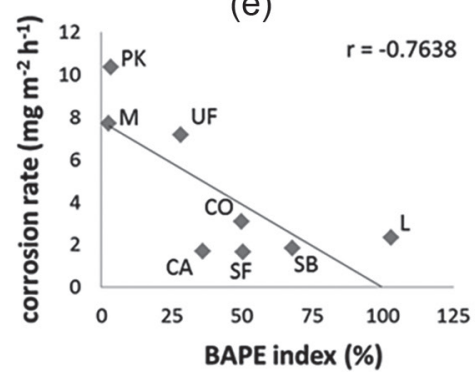

(c)

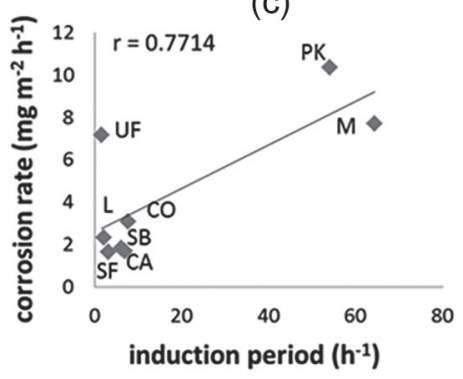

(f)

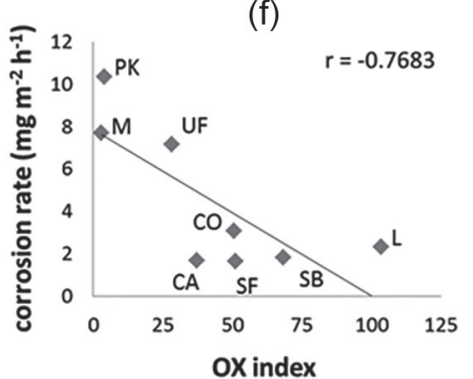

Figure 2. Plots of corrosion rate of metallic copper against: water content (a); acid value (b); induction period (c); APE index (d); BAPE index (e); and OX index (f) of prepared biodiesels. Oil source: soybean (SB), sunflower (SF), corn (CO), canola (CA), linseed (L), palm kernel (PK), macauba (M), and used frying oil (UF).

The relationship between the corrosion rate and the oxidative parameters are shown in Figures $2 \mathrm{c}-2 \mathrm{f}$. The literature ${ }^{10,13,33}$ has reported that the corrosiveness of biodiesel increases after its oxidation. Therefore, it was expected that the biodiesel with less oxidative stability would be more corrosive as a consequence of the formation of corrosive species during the oxidation process.

Figure $2 \mathrm{c}$ shows the relationship between the corrosion rate and the IP of eight different biodiesels. Among them, six (used frying oil (UF), linseed (L), corn (CO), canola $(\mathrm{CA})$, soybean $(\mathrm{SB})$, and sunflower $(\mathrm{SF}))$ present relatively low IP. Among these six, five (L, CO, CA, SB, and $\mathrm{SF})$ present the lowest corrosion rates of the eight studied. Therefore, biodiesels with low IP are less corrosive than those with high IP, demonstrating that the easily oxidable biodiesels are less corrosive compared to the more stable. Likewise, Figures 2d-2f show that the allylic and bis-allylic carbons (expressed by APE and BAPE contents) and the methyl esters of oleic, linoleic, and linolenic fatty acids (related to OX) inhibit the corrosion, while the literature ${ }^{12-14}$ reports that they favor biodiesel degradation. This behavior can be understood if molecular oxygen reacts preferentially with biodiesel rather than copper, leading to a low corrosion rate for this metal. Inversely, molecular oxygen reacts more rapidly with metallic copper if the biodiesel is more resistant to oxidation.

This is the case, for example, for the biodiesels from palm kernel and macauba oils, which present two of the three higher IP values observed and also present the two highest rates of corrosion (Figure 2c). On the other hand, the IP of the biodiesel from macauba oil $(64.3 \pm 0.3 \mathrm{~h})$ was quite different from the IP of the biodiesel from used frying oil $(1.61 \pm 0.02 \mathrm{~h})$. However, these two biodiesels have very similar corrosiveness $\left(7.7 \pm 1.1\right.$ vs. $\left.7.17 \pm 0.13 \mathrm{mg} \mathrm{m}^{-2} \mathrm{~h}^{-1}\right)$. This divergence does not occur in the oxidative stability parameters (OSP) associated with the FAME composition. In such cases, the lowest values of APE, BAPE, and OX indices occur in the three most corrosive biodiesels (from macauba, palm kernel, and used frying oil) (Figures 2d-2f). This fact suggests that the corrosion rate is more closely associated with the FAME composition than with the real biodiesel oxidative stability (measured by the IP value).

The good linear correlation ( $r=-0.94$, Figure $2 d$ ) of the APE index versus corrosion rate demonstrates that allylic carbons must have an important role in the corrosion rate. The reaction of allylic carbons with molecular oxygen dissolved in the biodiesel should decrease the amount of oxygen available to react with the metallic copper, reducing the rate of corrosion. For this reason, the linear correlation coefficient was negative.

It should also be noted that, although the literature relates that bis-allylic carbons are more susceptible to oxidation than allylic carbons, ${ }^{14}$ the linear correlation with the BAPE index $(r=-0.76)$ was smaller than with the APE index. Indeed, thermodynamically, the bis-allylic carbons are more reactive, but an oxidation process is also subject to kinetic control. Consequently, since the relative 
quantity of FAME with allylic carbon is higher than the relative quantity of FAME with bis-allylic carbon (see the APE and BAPE index values, in Table 2), the APE index becomes more relevant than the BAPE index to determine the FAME oxidation and the corrosion process.

As the corrosion rate decreases with the increase of the APE, BAPE and OX indices, which intrinsically are accompanied by an increase in the unsaturation number of the FAME composition, it is reasonable to conclude that unsaturated methyl esters act as sacrificial molecules, protecting the copper against corrosion. The relationship between the OSP associated with FAME composition and the corrosiveness of biodiesel should be the same for any biodiesel that does not suffer an advanced level of oxidation. The oxidation process decreases the level of unsaturation of the esters. This situation leaves molecular oxygen free to react with metallic copper, increasing, therefore, the corrosion rate. Additionally, the short chain acids formed at the end of the biodiesel degradation process will also increase the corrosion of the metal. Therefore, the results presented in this work are in agreement with the literature reports that an increase in the level of oxidation favors corrosion. However, so far as we know, an interesting aspect of the phenomenon of metallic copper oxidation by biodiesel, which has not been reported so far, is the fact that the more easily oxidizable biodiesel is less corrosive towards the metal.

\section{Corrosion rate prediction model}

The construction of consistent MLR models can provide mathematical correlations between the corrosion rate of metallic copper and $\mathrm{W}, \mathrm{AV}$, and FAME composition, leading to a better understanding of the mechanisms involved in the corrosion process.

When investigating the mechanism of copper corrosion by palm biodiesel, Fazal et al..$^{24}$ proposed that $\mathrm{O}_{2}$ and $\mathrm{H}_{2} \mathrm{O}$ present in the biodiesel would act as causative agents of corrosion, and, in the end, the $\mathrm{Cu}_{2} \mathrm{O}, \mathrm{CuO}, \mathrm{Cu}(\mathrm{OH})_{2}$, and $\mathrm{CuCO}_{3}$ produced are deposited on the metallic surface. Therefore, it is straightforward to expect a relationship between the presence of such compounds and the corrosion rate of metallic copper immersed in the fuel.

The copper surface is in contact mainly with the FAME (saturated and unsaturated), $\mathrm{H}_{2} \mathrm{O}$, and passivating agents $\left(\mathrm{Cu}_{2} \mathrm{O}, \mathrm{CuO}, \mathrm{Cu}(\mathrm{OH})_{2}\right.$ and $\left.\mathrm{CuCO}_{3}\right)$ deposited on the metal, according to the illustration in Figure 3.

Thus, it is reasonable to assume that the global loss of metallic copper mass is expressed as the sum of the losses of mass that occur in each region of the metal surface in contact with these substances, according to equation 5 :

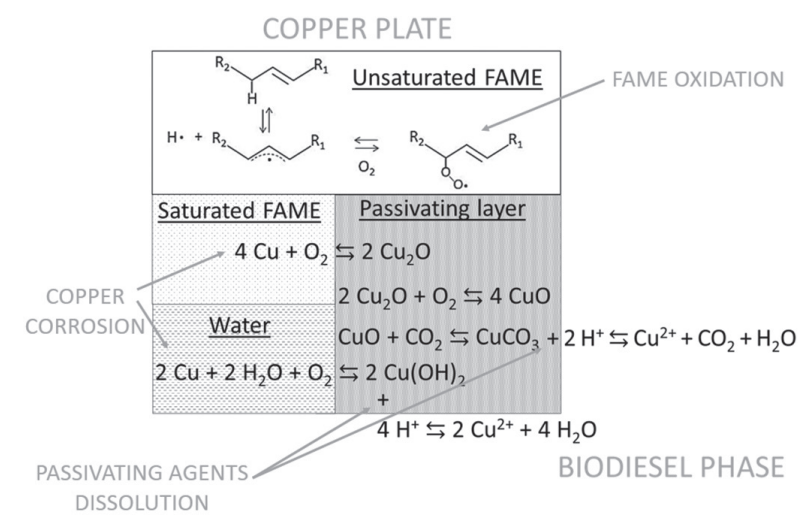

Figure 3. General scheme of a copper plate immersed in biodiesel with FAME (saturated and unsaturated), water, and a passivation layer deposited on the metallic surface. The reactions for corrosion and the formation of passivation agents in each region are in accordance with those proposed by Fazal et al. $^{24}$

$\Delta \mathrm{m}=\Delta \mathrm{m}_{\mathrm{H}_{2} \mathrm{O}}+\Delta \mathrm{m}_{\mathrm{pa}}+\Delta \mathrm{m}_{\mathrm{FAME}}$

where: $\Delta \mathrm{m}$ is the global loss of metallic copper mass; $\Delta \mathrm{m}_{\mathrm{H}_{2} \mathrm{O}}, \Delta \mathrm{m}_{\mathrm{pa}}$, and $\Delta \mathrm{m}_{\mathrm{FAME}}$ are the loss of mass of the copper plate due to contact with water, passivating agents, and FAME, respectively. Considering that $\mathrm{O}_{2}$ acts in the oxidation process only when dissolved in the liquid phases, the terms $\Delta \mathrm{m}_{\mathrm{H}_{2} \mathrm{O}}$ and $\Delta \mathrm{m}_{\mathrm{FAME}}$ encompass this aspect.

The terms of equation 5 can be written as a function of area covered by each substance, according to equations 6-8:

$\Delta \mathrm{m}_{\mathrm{H}_{2} \mathrm{O}}=\mathrm{c}_{1} \mathrm{~A}_{\mathrm{H}_{2} \mathrm{O}}+\mathrm{b}_{1}$

$\Delta \mathrm{m}_{\mathrm{pa}}=-\mathrm{c}_{2} \mathrm{~A}_{\mathrm{pa}}+\mathrm{b}_{2}$

$\Delta \mathrm{m}_{\mathrm{FAME}}=\mathrm{c}_{3} \mathrm{~A}_{\mathrm{FAME}}+\mathrm{b}_{3}$

where $\mathrm{A}_{\mathrm{H}_{2} \mathrm{O}}, \mathrm{A}_{\mathrm{pa}}$, and $\mathrm{A}_{\mathrm{FAME}}$ are respectively: (i) the surface area of copper in contact with water; (ii) the area of the plate of copper inactivated by passivating agents; (iii) the area of the copper plate in contact with FAME. $c_{x}$ and $b_{x}$ are the respective angular and linear coefficients of the equations. The values of $b_{1}$ and $b_{3}$ are equal to zero, because, theoretically, $\Delta \mathrm{m}_{\mathrm{H}_{2} \mathrm{O}}$ and $\Delta \mathrm{m}_{\mathrm{FAME}}$ are equal to zero in absence of water and FAME, respectively. The $b_{2}$ coefficient represents the loss of mass when there are no passivating agents $\left(A_{p a}=0\right)$, and should be greater than zero. The negative signal of $c_{2}$ is due to the coating of the copper plate by passivating agents decreasing the $\Delta \mathrm{m}_{\mathrm{pa}}$ value. If the copper plate is $100 \%$ coated by passivating agents, then $\Delta \mathrm{m}_{\mathrm{pa}}=0$.

$\Delta \mathrm{m}_{\mathrm{H}_{2} \mathrm{O}}$ occurs due to water condensation on the metallic surface, and molecular oxygen is the oxidizing agent of the metallic copper (Figure 3). ${ }^{10,24}$ As the surface area of the metallic copper covered by water must be proportional to $\mathrm{W}$, then the equation 6 becomes equation 9 . So, $\mathrm{W}$ was used to estimate $\Delta \mathrm{m}_{\mathrm{H}_{2} \mathrm{O}}$, and the coefficient $\mathrm{c}_{1}^{\prime}$ would present a 
positive value. The microbial corrosion due to the water condensation may be neglected due to the high immersion test temperature $\left(60^{\circ} \mathrm{C}\right)$, which killed the microbes.

$\Delta \mathrm{m}_{\mathrm{H}_{2} \mathrm{O}}=\mathrm{c}_{1}^{\prime} \mathrm{W}+\mathrm{b}_{1}^{\prime}$

The passivating agents deposited on the metal in the form of copper compounds $\left(\mathrm{Cu}_{2} \mathrm{O}, \mathrm{CuO}, \mathrm{Cu}(\mathrm{OH})_{2}\right.$ and $\mathrm{CuCO}_{3}$ ) inhibit corrosion. The area covered by passivation agents $\left(\mathrm{A}_{\mathrm{pa}}\right)$ may be related to $\mathrm{AV}$, because the free acid in biodiesel may promote the dissolution of the passivating agents (Figure 3), and the copper will be less protected by the passivation layer becoming more susceptible to corrosion. An increase of $A V$ will decrease $A_{p a}$ and, consequently, $\Delta m_{p a}$ will be higher. Thus, equation 7 becomes equation 10 and the $c_{2}^{\prime}$ coefficient would be positive.

$\Delta \mathrm{m}_{\mathrm{pa}}=\mathrm{c}_{2}^{\prime} \mathrm{AV}+\mathrm{b}_{2}^{\prime}$

The mass loss of the metallic copper surface in contact with FAME, $\Delta \mathrm{m}_{\text {FAME }}$, must be related to FAME composition, being caused by molecular oxygen (Figure 3). Two terms could be used to estimate $\Delta \mathrm{m}_{\mathrm{FAME}}$, according to the following discussions: number of unsaturated bonds $\left(\mathrm{N}_{\text {UNSAT }}\right)$ in biodiesel or the concentration of $\mathrm{O}_{2}$ available to attack the copper plate.

Unsaturated bonds contribute to the adsorption of corrosion inhibitors on the metallic surface, protecting the metal against the corrosion caused by acid attack. ${ }^{34}$ Similarly, unsaturated FAME could be adsorbed on a copper surface, protecting it against corrosion, and the $\mathrm{O}_{2}$ will react preferentially with the allylic or bis-allylic carbons (Figure 3). Corrosion will occur in the region of the surface of the copper plate that is in contact with saturated FAME (Figure 3). In this case, only a fraction of $\mathrm{A}_{\text {FAME }}$ will undergo $\mathrm{O}_{2}$ attack. Thus, equation 8 could best be written as:

$\Delta \mathrm{m}_{\mathrm{FAME}}=\mathrm{c}_{3} \mathrm{~A}_{\mathrm{SFAME}}+\mathrm{b}_{3}$

where $\mathrm{A}_{\text {SFAME }}$ is the area covered by saturated FAME and $b_{3}$, as in equation 8 , is equal to zero. Equation 8 can also be written as a function of the area covered by unsaturated FAME $\left(\mathrm{A}_{\text {UFAME }}\right)$ becoming:

$\Delta \mathrm{m}_{\mathrm{FAME}}=\mathrm{c}_{3} \mathrm{~A}_{\mathrm{UFAME}}+\mathrm{b}_{3}$

The coefficient $c_{3}$ will be negative because coating the copper plate will decrease the mass loss. In equation 12 , the linear coefficient $b_{3}$ will be greater than zero and equal to $\Delta \mathrm{m}_{\text {FAME }}$ when there is no unsaturated FAME. The area covered by unsaturated FAME must be directly proportional to $\mathrm{N}_{\mathrm{UNSAT}}$ in biodiesel and equation 12 becomes:

$\Delta \mathrm{m}_{\mathrm{FAME}}=-\mathrm{c}_{3}^{\prime} \mathrm{N}_{\mathrm{UNSAT}}+\mathrm{b}_{3}^{\prime}$

$\mathrm{N}_{\mathrm{UNSAT}}$ can be calculated according equation 14:

$\mathrm{N}_{\text {UNSAT }}=\left(\mathrm{n}_{\mathrm{a}} \mathrm{A}_{\mathrm{a}}+\mathrm{n}_{\mathrm{b}} \mathrm{A}_{\mathrm{b}}+\mathrm{n}_{\mathrm{c}} \mathrm{A}_{\mathrm{c}}+\ldots\right) / 100$

where $n_{x}$ is the unsaturation number of a specific FAME, and $\mathrm{A}_{\mathrm{x}}$ is the percentage content of each FAME in biodiesel. The $\mathrm{N}_{\mathrm{UNSAT}}$ values are listed in Table 1 .

The adsorption of molecules on the metal surface is well related in unsaturated chains with conjugated double bonds, ${ }^{35}$ which is not the case with the methyl esters that constitute the biodiesels used (Table 1). Therefore, it is also possible that the unsaturated FAME is not well adsorbed onto the surface of the copper plate and equations 11,12 , and 13 are not valid. In this case, $\Delta \mathrm{m}_{\mathrm{FAME}}$ could be correlated to the $\mathrm{O}_{2}$ available to oxidize the copper plate. If biodiesel is hardly oxidized, more $\mathrm{O}_{2}$ will be available to react with the metal, increasing the corrosion rate, in comparison to more easily oxidized biodiesel. On the contrary, if the biodiesel presents high oxidability, the $\mathrm{O}_{2}$ will react with the FAME to a greater extent, and, consequently, the copper plate will be less corroded. As the oxidability of biodiesel is related to IP and to the APE, BAPE, and OX indices (here generalized as OSP), $\Delta \mathrm{m}_{\mathrm{FAME}}$ could be written as a function of these parameters according to equations 15 and 16, instead of the area of the copper surface covered by FAME ( $\left.\mathrm{A}_{\mathrm{FAME}}\right)$ previously described by equation 8 .

$\Delta \mathrm{m}_{\mathrm{FAME}}=\mathrm{c}_{4} \mathrm{IP}+\mathrm{b}_{4}$

$\Delta \mathrm{m}_{\mathrm{FAME}}=-\mathrm{c}_{5} \mathrm{OSP}+\mathrm{b}_{5}$

In equation $15, c_{4}$ is positive, because the increase of the IP value is related to the decrease of FAME oxidation. Consequently, the $\mathrm{O}_{2}$ present will be more available to react with copper, increasing the mass loss of the plate. In the correlation expressed by equation $16, \mathrm{c}_{5}$ is negative, because FAME oxidation increases with an increase of the OSP value, leaving less $\mathrm{O}_{2}$ available to react with copper. Consequently, a decrease of the $\Delta \mathrm{m}_{\text {FAME }}$ will be observed.

In accordance with the previous considerations, the mass loss $(\Delta \mathrm{m})$ in equation 5 can be written, according to equations 17,18 and 19 , as a function of $\mathrm{W}, \mathrm{AV}, \mathrm{N}_{\text {UNSAT }}$, IP, and OSP:

$\Delta \mathrm{m}=\mathrm{c}_{1}^{\prime} \mathrm{W}+\mathrm{c}_{2}^{\prime} \mathrm{AV}-\mathrm{c}_{3}^{\prime} \mathrm{N}_{\mathrm{UNSAT}}+\left(\mathrm{b}_{1}^{\prime}+\mathrm{b}_{2}^{\prime}+\mathrm{b}_{3}^{\prime}\right)$

$\Delta \mathrm{m}=\mathrm{c}_{1}^{\prime} \mathrm{W}+\mathrm{c}_{2}^{\prime} \mathrm{AV}-\mathrm{c}_{4} \mathrm{IP}+\left(\mathrm{b}_{1}^{\prime}+\mathrm{b}_{2}^{\prime}+\mathrm{b}_{4}\right)$

$\Delta \mathrm{m}=\mathrm{c}_{1}^{\prime} \mathrm{W}+\mathrm{c}_{2}^{\prime} \mathrm{AV}-\mathrm{c}_{5} \mathrm{OSP}+\left(\mathrm{b}_{1}^{\prime}+\mathrm{b}_{2}^{\prime}+\mathrm{b}_{5}\right)$ 
Replacing $\Delta \mathrm{m}$ of equation 1 by equations $17-19$ and holding the $\mathrm{A}$ and t parameters constant, equations 20, 21 and 22 can be proposed:

corrosion rate $=\mathrm{a}_{\mathrm{W}} \mathrm{W}+\mathrm{a}_{\mathrm{AV}} \mathrm{AV}-\mathrm{a}_{\mathrm{N}} \mathrm{N}_{\mathrm{UNSAT}}+\mathrm{o}$

corrosion rate $=a_{W} W+a_{A V} A V+a_{I P} I P+p$

corrosion rate $=a_{W} W+a_{A V} A V-a_{O S P} O S P+q$

where $\mathrm{a}_{\mathrm{W}}, \mathrm{a}_{\mathrm{AV}}, \mathrm{a}_{\mathrm{N}}, \mathrm{a}_{\mathrm{IP}}$ and $\mathrm{a}_{\mathrm{OSP}}$ are the respective coefficients of corrosion related to each parameter (they will have the same signs as $\mathrm{c}_{1}^{\prime}, \mathrm{c}_{2}^{\prime}, \mathrm{c}_{3}^{\prime}, \mathrm{c}_{4}$ and $\mathrm{c}_{5}$, respectively, as discussed above); $\mathrm{o}, \mathrm{p}$, and $\mathrm{q}$ are the linear coefficients from the sum of the $b_{1}^{\prime}, b_{2}^{\prime}, b_{3}^{\prime}, b_{4}$ and $b_{5}$ coefficients, according to equations 17-19. All coefficients of equations 20-22 can be determined empirically by multiple linear regression.

Table 3 shows the MLR models obtained by combining the parameters of equations 20-22. Additionally, a prediction model was created using only the APE index (without $\mathrm{W}$ and $\mathrm{AV}$ ), because this parameter gave the best linear correlation with the corrosion rate (Figure 2d). The predicted and experimental corrosion rate values are shown in Table 4.

As can be seen from Table 3 , the use of IP as an oxidative stability parameter gave a weaker model (model 2) than those with oxidation parameters related to FAME composition (models 3-6) and to the $\mathrm{N}_{\mathrm{UNSAT}}$ (model 1). Model 2 presents no statistically significant predictive capability at significance level of 0.05 ( $F$-value $<0.05)$.

In the other MLR models (1, 3, 4, and 5), all variables related to the FAME composition $\left(\mathrm{N}_{\mathrm{UNSAT}}\right.$, APE, BAPE, and OX, respectively) present a statistically significant predictive capacity at significance level of 0.05 ( $p$-values $<0.05$, see Table 5 ) in relation to the other independent variables (W and $\mathrm{AV}$ ). The same trend was observed for AV in models 1, 4, and 5.

The $\mathrm{W}$ variable, on the other hand, did not present statistically significant predictive capacity in any model ( $p$-values $>0.05$, Table 5), but this does not mean that water is not an agent of corrosion. The amount of water is substantially lower in biodiesel than the amount of FAME. Therefore, the area of the copper plate in contact with water is very small. Consequently, the predictive capacity of the model related corrosion caused by $\mathrm{W}$ becomes statistically insignificant.

These results reinforce the idea that the parameters more strictly related to the oxidizable fatty chain content, and, ultimately, unsaturated chains, are more important than the $\mathrm{IP}$ value and $\mathrm{W}$ for the corrosion rate. $\mathrm{AV}$ is also relevant;

Table 3. Models of linear regression constructed using W, AV, $\mathrm{N}_{\mathrm{UNSAT}}$, IP, and OSP (APE, BAPE and OX indices)

\begin{tabular}{lccccc}
\hline Model & Equation $($ corrosion rate $=$ ) & R-multiple & R-squared & Standard error & $F$-value \\
\hline 1 & $0.006 \mathrm{~W}+31.34 \mathrm{AV}-4.97 \mathrm{~N}_{\mathrm{UNSAT}}-2.27$ & 0.97 & 0.94 & 1.12 & 0.007 \\
2 & $0.001 \mathrm{~W}+31.22 \mathrm{AV}+0.065 \mathrm{IP}+2.27$ & 0.84 & 0.70 & 2.48 & 0.159 \\
3 & $0.004 \mathrm{~W}+10.15 \mathrm{AV}-0.058 \mathrm{APE}+8.93$ & 0.96 & 0.92 & 0.28 & 1.47 \\
4 & $0.007 \mathrm{~W}+47.53 \mathrm{AV}-0.073 \mathrm{BAPE}-3.14$ & 0.95 & 0.89 & 0.90 & 0.020 \\
5 & $0.007 \mathrm{~W}+47.28 \mathrm{AV}-7.37 \mathrm{OX}-3.060$ & 0.95 & 0.90 & 1.28 & 0.019 \\
6 & $-0.055 \mathrm{APE}+12.14$ & 0.94 & 0.88 & 1.001 \\
\hline
\end{tabular}

W: water content; $\mathrm{AV}$ : acid value; $\mathrm{N}_{\mathrm{UNSAT}}$ : number of unsaturated bonds; IP: induction period; APE: allylic position equivalent; BAPE: bisallylic position equivalent; OX: oxidability.

Table 4. Corrosion rates predicted by linear regression models and experimental values

\begin{tabular}{|c|c|c|c|c|c|c|c|}
\hline \multirow{2}{*}{ Biodiesel } & \multicolumn{6}{|c|}{ Predicted corrosion rate / $\left(\mathrm{mg} \mathrm{m}^{-2} \mathrm{~h}^{-1}\right)$} & \multirow{2}{*}{$\begin{array}{c}\text { Experimental } \\
\text { corrosion rate } \\
\left(\mathrm{mg} \mathrm{m}^{-2} \mathrm{~h}^{-1}\right)\end{array}$} \\
\hline & Model 1 & Model 2 & Model 3 & Model 4 & Model 5 & Model 6 & \\
\hline Sunflower & 1.19 & 1.50 & 1.35 & 1.09 & 1.09 & 1.98 & 1.65 \\
\hline Canola & 2.99 & 2.13 & 1.86 & 3.46 & 3.45 & 1.76 & 1.68 \\
\hline Corn & 2.65 & 2.83 & 2.53 & 2.76 & 2.76 & 2.73 & 3.09 \\
\hline Linseed & 2.24 & 3.45 & 3.34 & 1.79 & 1.79 & 2.08 & 2.33 \\
\hline Used frying oil & 5.72 & 3.57 & 6.01 & 5.41 & 5.45 & 6.16 & 7.17 \\
\hline Soybean & 2.34 & 4.67 & 2.20 & 3.09 & 3.06 & 2.86 & 1.84 \\
\hline Macauba & 8.40 & 8.48 & 9.26 & 7.60 & 7.60 & 9.72 & 7.71 \\
\hline Palm kernel & 10.27 & 9.17 & 9.25 & 10.61 & 10.62 & 8.51 & 10.35 \\
\hline
\end{tabular}


Table 5. $p$-Values of independent variables for models 1-6

\begin{tabular}{lccccccc}
\hline \multirow{2}{*}{ Model } & \multicolumn{7}{c}{ Variable } \\
\cline { 2 - 7 } & $\mathrm{W}$ & $\mathrm{AV}$ & $\mathrm{N}_{\text {UNSAT }}$ & IP & APE & BAPE & - \\
\hline 1 & 0.099 & 0.049 & 0.0084 & - & - & OX \\
2 & 0.86 & 0.32 & - & 0.28 & & \\
3 & 0.24 & 0.54 & - & - & - & 0.015 & -026 \\
4 & 0.18 & 0.027 & - & - & - & - & -0.025 \\
5 & 1.7 & 0.026 & - & - & 0.00058 & - \\
\hline
\end{tabular}

$\mathrm{W}$ : water content; $\mathrm{AV}$ : acid value; $\mathrm{N}_{\mathrm{UNSAT}}$ : number of unsaturated bonds; IP: induction period; APE: allylic position equivalent; BAPE: bisallylic position equivalent; OX: oxidability.

however, as the influence of the APE index is highlighted, the $\mathrm{AV}$ variable does not present a statistically significant predictive capacity in model 3 ( $p$-value $>0.05$, Table 5 ). Because of this, model 6 has a high predictive capacity in comparison to other models (Table 3).

The proposed models presented in Table 3 are not presented with the intention of employing them as an alternative for the prediction of corrosion rates, even though they may be used for this purpose (except model 2). The immersion tests are simpler and cheaper for the determination of corrosion rate than the required methods for the determination of W, AV, IP, and FAME composition for the prediction of corrosion rates by the proposed models. However, an important aspect of these models should be highlighted: all the signs of the independent variable coefficients, $\mathrm{N}_{\mathrm{UNSAT}}(-)$, IP (+), $\operatorname{APE}(-)$, BAPE (-), OX (-), $\mathrm{W}(+)$, and $\mathrm{AV}(+)$, are in accordance with those previously predicted for coefficients $a_{1}-a_{3}$ of equations 20-22. This fact supports the proposed description of the main phenomena that govern the corrosive process which occurs on the metallic copper surface and in the biodiesel phase (Figure 3).

Therefore, MLR models 3-5 present special interest as they clearly suggest that the oxidative stability, W, and AV are directly related to the corrosion rate mechanism. These models also indicate that the APE, BAPE, and OX indices decrease the corrosion rate on the copper plate as they compete for the $\mathrm{O}_{2}$ present in the biodiesel due to their own oxidation processes. In parallel, the good fit of the corrosion rate with experimental values obtained by model 1 (Table 3 and 4) also suggests that unsaturated FAME protects the copper plate against $\mathrm{O}_{2}$ attack due to its own adsorption on the metallic surface.

\section{Conclusions}

Biodiesel corrosivity is related to the content of methyl esters of oleic (C18:1), linoleic (C18:2) and linolenic (18:3) acids, more specifically the levels of unsaturated methyl esters. Biodiesels with low IP were less corrosive than those with high IP, demonstrating that easily oxidizable biodiesels are less corrosive than the less oxidizable ones. Likewise, allylic and bis-allylic carbons (expressed by APE and BAPE indices) inhibit the corrosion, although they favor the oxidation of biodiesel. A higher correlation between corrosion rate and $\mathrm{AV}$ was also observed, which indicates that $\mathrm{AV}$ is an important parameter in the corrosion process.

The prediction models that relate the corrosion rate variable to the average unsaturation number, parameters of oxidative stability, AV, and $\mathrm{W}$ can explain the corrosion of metallic copper caused by biodiesel. More easily oxidizable biodiesel is less corrosive than hardly oxidizable biodiesel, because the dissolved $\mathrm{O}_{2}$ should react with unsaturated FAME, which would adsorb on the copper surface acting as "sacrificial molecules" to protect the copper against corrosion. The water condensed on the metallic surface will promote copper oxidation due to the dissolved $\mathrm{O}_{2}$, but the predictive capacity of the corrosion rate related to $\mathrm{W}$ is statistically insignificant because of the low amount of water in biodiesel in comparison to the amount of FAME. Although the corrosion reaction progressively produces a passivation layer on the copper surface, free acids will react with these byproducts, preventing a decrease of the exposed surface area of the metal and, consequently, avoiding a decrease in the rate of corrosion.

\section{Acknowledgments}

This study was financed in part by the Coordenação de Aperfeiçoamento de Pessoal de Nível Superior (CAPES, Brazil), finance code 001, and by the Conselho Nacional de Desenvolvimento Científico e Tecnológico (CNPq, Brazil), finance codes 404808/2013-1, 420868/2016-0 and 304605/2016-6. 


\section{References}

1. Meher, L. C.; Sagar, D. V.; Naik, S. N.; Renewable Sustainable Energy Rev. 2006, 10, 248.

2. Damanik, N.; Ong, H. C.; Tong, C. W.; Mahlia, T. M. I.; Silitonga, A. S.; Environ. Sci. Pollut. Res. 2018, 25, 15307.

3. Sirviö, K.; Heikkilä, S.; Help, R.; Niemi, S.; Hiltunen, E.; Agron. Res. 2018, 16, 1237.

4. Chandran, D.; Kiat, N. G.; Nang, H. L. L.; Suyin, G.; Choo, Y. M.; Jahis, S.; J. Oil Palm Res. 2016, $28,64$.

5. Haryono, I.; Ma’ruf, M.; Setiapraja, H.; Int. J. Energy Environ. 2016, 7, 383.

6. EN 16709:2015: Automotive Fuels - High FAME Diesel Fuel (B20 and B30) - Requirements and Test Methods, European Committee for Standardization, Brussels, Belgium, 2015.

7. Conselho Nacional de Política Energética (CNPE); Estabelece a Adição Obrigatória, em Volume, de Dez por Cento de Biodiesel ao Óleo Diesel Vendido ao Consumidor Final; Resolução CNPE No. 23 2017, de 09.11.2017, available at http://www.mme.gov. br, accessed on April 25, 2019.

8. Haseeb, A. S. M. A.; Masjuki, H. H.; Ann, L. J.; Fazal, M. A.; Fuel Process. Technol. 2010, 91, 329.

9. McCornick, R. L.; Ratcliff, M.; Moens, L.; Lawrence, T.; Fuel Process. Technol. 2007, 88, 651.

10. Fazal, M. A.; Haseeb, A. S. M. A.; Masjuki, H. H.; Fuel Process. Technol. 2010, 91, 1308.

11. Ahmmad, M. S.; Hassan, M. B. H.; Kalam, M. A.; Int. J. Green Energy 2018, 15, 393.

12. Zuleta, E. C.; Baena, L.; Rios, L. A.; Calderón, J. A.; J. Braz. Chem. Soc. 2012, 23, 2159.

13. Pullen, J.; Saeed, K.; Renewable Sustainable Energy Rev. 2012, 16, 5924.

14. Knothe, G.; Dunn, R. O.; J. Am. Oil Chem. Soc. 2003, 80, 1021.

15. Niczke, L.; Czechowski, F.; Gawel, I.; Prog. Org. Coat. 2007, 59, 304.

16. Tsuchiya, T.; Shiotani, H.; Goto, S.; Sugiyama, G.; Maeda, A.; SAE [Tech. Pap.] 2006, 01, 3303.

17. Singha, B.; Korstadb, J.; Sharmaa, Y. C.; Renewable Sustainable Energy Rev. 2012, 16, 3401.

18. Haseeb, A. S. M. A.; Fazal, M. A.; Jahirul, M. I.; Masjuki, H. H.; Fuel 2011, 90, 922.
19. Sylvester O.; Adams, F. V.; Okoro, L. N.; Int. J. Sci. Eng. Res. 2015, 6, 546.

20. Sorate, K. A.; Bhale, P. V.; J. Sci. Ind. Res. 2012, 72, 48.

21. Kaul, S.; Saxena, R. C.; Kumar, A.; Negi, M. S.; Bhatnagar, A. K.; Goyal, H. B.; Gupta, A. K.; Fuel Process. Technol. 2007, $88,303$.

22. Sgroi, M.; Bollito, G.; Saracco, G.; Specchia, S.; J. Power Sources 2015, 149, 8.

23. Geller, D. P.; Adams, T. T.; Goodrum, J. W.; Pendergrass, J.; Fuel Process. Technol. 2008, 87, 92.

24. Fazal, M. A.; Haseeb, A. S. M. A.; Masjuki, H. H.; Corros. Sci. 2013, 67, 50.

25. Aquino, I. P.; Hernandeza, R. P. B.; Chicoma, D. L.; Pinto, H. P. F.; Aokia, I. V.; Fuel 2012, 102, 795.

26. Sarin, A.; Arora, R.; Singh, N. P.; Sharma, M. P.; Malhotra, R. K.; Energy 2009, 34, 1271.

27. EN 14112:2003: Fat and Oil Derivatives - Fatty Acid Methyl Esters (FAME); Determination of Oxidation Stability (Accelerated Oxidation Test), European Committee for Standardization, Brussels, Belgium, 2003.

28. EN ISO 12937:2000: Petroleum Products - Determination of Water-Coulometric Karl Fischer Titration Method, European Committee for Standardization, Brussels, 2000.

29. Aricetti, J. A.; Tubino, M.; Fuel 2012, 95, 659.

30. ASTM G1-03: Standard Practice for Preparing, Cleaning, and Evaluating Corrosion Test Specimens, ASTM International, West Conshohocken, PA, 2003.

31. Knothe, G.; J. Am. Oil Chem. Soc. 2002, 79, 847.

32. Neff, W. E.; Selke, E.; Mounts, T. L.; J. Am. Oil Chem. Soc. 1992, 69, 111.

33. Kumar, N.; Fuel 2017, 190, 328.

34. Kumari, P. P.; Shetty, P.; Rao, S. A.; Arabian J. Chem. 2017, 10,653 .

35. Alobaidy, A.; Kadhum, A.; Al-Baghdadi, S.; Al-Amiery, A.; Kadhum, A.; Yousif, E.; Mohamad, A.; Int. J. Electrochem. Sci. 2015, 10, 3961.

Submitted: December 20, 2018 Published online: April 30, 2019 